\title{
A feminização do jornalismo e a ausência da perspectiva de gênero nas editoriais de tecnologia no Brasil
}

\author{
Paula Melani Rocha
}

Doutora; Universidade Estadual de Ponta Grossa paulamelani@gmail.com

\section{Andressa Kikuti Dancosky}

Mestre; Universidade Estadual de Ponta Grossa

andressakikuti@gmail.com

\section{Resumo}

A participação feminina no jornalismo brasileiro é maior que a masculina a partir do século XXI. No entanto, o processo de produção jornalística ainda é o mesmo no que diz respeito à perspectiva dos estudos de gênero. Há uma predominância de fontes masculinas nos discursos jornalísticos, principalmente nas editorias de política e de economia. Nesse sentido, o presente artigo tem como proposta olhar para uma editoria nova, se comparada com as de política e de economia - trata-se da editoria de tecnologia, em versão online. O objetivo é verificar a presença de mulheres tanto como produtoras de notícias como de fontes, bem como as representações de gênero veiculadas no conteúdo informativo, incluindo fotos e temas das notícias. A metodologia inclui pesquisa bibliográfica em estudos de jornalismo e gênero, sobre a teoria do newsmaking e conceito de gênero. Observou-se quatro jornais brasileiros, Gazeta do Povo, Correio Braziliense, Folha de São Paulo e O Estado de São Paulo, a partir de categorias jornalísticas estabelecidas com base no referencial teórico em jornalismo. A análise das categorias fundamentou-se nas discussões de gênero. Os resultados apontam que o número de profissionais femininas atuantes na editoria de tecnologia é praticamente inexistente e que a preocupação com questões de gênero é mínima nessas editorias. Tal percepção reforça a importância da continuidade dos estudos e dos debates nesta área.

\section{Palavras-chave}

Jornalismo. Editorias de tecnologia. Representações de gênero. Newsmaking. Feminização do Jornalismo. 


\section{Apontamentos iniciais: a ocupação feminina nas redações}

A partir das últimas décadas do século $\mathrm{XX}$ e início do século $\mathrm{XXI}$, o processo comunicacional e o jornalismo ocidental vêm passando por desdobramentos contínuos ocasionados pela aceleração das transformações tecnológicas e do próprio modo de produção capitalista. Para muitos teóricos está se configurando um novo paradigma do jornalismo, o qual inclui tanto o processo de produção jornalística quanto modelos de gestão. Entre as concordâncias desse novo panorama está a crescente feminização das redações em alguns países ocidentais. Neveu (2005) aponta que na Nova Zelândia e na Finlândia, as mulheres representam mais de 45\% do mercado de trabalho. Na França, embora venha aumentando a participação feminina, a ocupação é desigual dependendo do veículo. Elas representam: “52\% em revistas, 42\% em semanários de informação, 39\% na imprensa diária francesa, 30\% nas televisões francesas e 26\% na imprensa regional diária" (NEVEU, 2005, p. 33). Em Portugal, segundo dados do Sindicato dos Jornalistas, referentes a 2007, o número de profissionais femininas estava muito próximo ao de homens: dos 5.749 jornalistas sindicalizados, 2.883 eram homens e 2.866 mulheres.

No Brasil, uma pesquisa realizada em 2012 pelo programa de pós-graduação em Sociologia Política da Universidade Federal de Santa Catarina (UFSC), em parceria com a Federação Nacional dos Jornalistas (FENAJ), com uma amostragem de 2.731 jornalistas brasileiros, revela que as mulheres representam $63,7 \%$ do mercado (36,3\% são homens) (PERFIL..., 2013).

No Peru não há um levantamento sistematizado sobre o número de mulheres e homens atuando no mercado de trabalho em jornalismo, porém cresce gradativamente o número de mulheres nas redações e, também, nos 34 cursos de comunicação existentes no país.

Segundo Zuliana Laínez, dirigente da Associação Nacional de Jornalistas, as mulheres ocupam entre $65 \%$ a $72 \%$ das salas nos primeiros anos da faculdade no Peru. No entanto, nos postos de direção dos meios de comunicação impressos, audiovisuais e digitais, os homens ainda dominam e é baixa a presença de profissionais femininas nos cargos de produtoras, executivas, chefes de redação, editoras ou diretoras. "É preciso reconhecer os fatos: as mulheres dominam as redações em quantidade, mas não mandam", disse à Agência de Notícias Inter Press Service, Zuliana Laínez, durante o III Encontro Nacional da Mulher Jornalista, realizado em 2009 em Lima (ROSALES, 2009). 
Em Cuba, o número de profissionais mulheres atuando no mercado de trabalho é equivalente ao dos homens e elas também desempenham funções de chefia nas redações. Segundo Guerra (2014), dos 4.148 jornalistas afiliados à Unión de Periodistas de Cuba, 2.064 são mulheres. Como pontua a autora:

As mulheres passaram a assumir os principais cargos de direção nos meios. Mais de 70 estão à frente de veículos de comunicação, incluindo nacionais e internacionais. É que as mulheres em Cuba são 49,8\% da força que ocupa cargos jornalísticos nos meios de comunicação nacionais, provinciais e municipais. (GUERRA, 2014, p. 2, tradução nossa).

As mulheres em Cuba também são maioria nas salas de aula: representam cerca de 80\% dos graduandos em jornalismo. Frente a esses números, para Guerra (2014) a tendência nos próximos anos é de que aumenteo número de jornalistas no mercado de trabalho. Outro dado interessante apontado pela autora diz respeito à participação de jornalistas no parlamento cubano: dos 18 profissionais, 10 são mulheres.

O processo da participação feminina no jornalismo não foi um movimento isolado, ao contrário, ele está inserido no contexto ocidental de transformação e introdução da mulher no mercado de trabalho, uma atitude que ganhou força no século XX. Tal avanço é consequência das transformações econômicas, sociais e políticas de cada país. A vida de homens e mulheres tem sofrido grandes transformações, em decorrência de mudanças de ordem social, econômica, política e tecnológica que ocorreram no mundo. Tais transformações acabam também reconfigurando a construção simbólica do sentido de homem e mulher.

Contudo, como aponta Torres (2000), os meios de comunicação, apesar da modernidade, não têm incorporado plenamente essas mudanças, que são significativas na representação da ordem socialmente estabelecida nas relações de gênero.

Dados do Projeto Global de Observação da Mídia, realizado em 2005, em países da América Latina, por exemplo, apontam que 57\% dos apresentadores de televisão eram mulheres, mas apenas 29\% das notícias eram redigidas por pessoas do sexo feminino. Ao mesmo tempo, somente $23 \%$ das chamadas "notícias sérias" foram cobertas ou redigidas por profissionais femininas, que por sua vez atuavam com maior frequência no que é definido como informação "leve", como assuntos sociais, família, arte e vida. Nessa área, mais de $40 \%$ dos profissionais eram mulheres.

Nesse sentido, como bem coloca Torres (2000, p. 21, tradução nossa): 
As transformações dos cenários midiáticos evidenciam um desnível entre seu desenvolvimento tecnológico e os sentidos de seus conteúdos. A reflexão sobre cada um dos meios e suas respectivas produções permite repensar os papéis e funções sociais dos meios frente a estas novas condições.

A história normalmente é contada pela perspectiva dominante, os outros atores sociais ficam ocultos ou ocupam o lugar que lhes é determinado e imposto, impossibilitados de ecoar, dando continuidade ao modus operandi. Isso não significa que esses outros atores sociais também não são sujeitos da história, pois ajudam a construí-la, interagindo e muitas vezes em movimentos dialéticos.

Este artigo tem por objetivo verificar a participação de profissionais femininas nas editorias de tecnologia e a presença das representações de gênero neste segmento. A reflexão é fruto das discussões travadas no grupo de pesquisa Jornalismo e Gênero, da Universidade Estadual de Ponta Grossa (UEPG).

A escolha pela editoria de tecnologia foi proposital, pois se trata de um tema atual envolto à sociedade contemporânea e digital. Além disso, dados do IBGE (2011) apontam a mulher como consumidora em potencial em tecnologia. 0 percentual de mulheres que acessam a internet para buscar informações e serviços é maior que o de homens, respectivamente $25 \%$ e 23,9\%. Em relação à posse de aparelhos de celular, as mulheres ultrapassaram os homens, são $69,5 \%$ contra $68,7 \%$. As categorias de análise utilizadas procuraram dar conta de compreender o papel da mulher no jornalismo produzido para as editorias de tecnologia. Tais classificações se inspiram no trabalho de Torres (2000) e são as seguintes:

a) repórteres: dentre as matérias de destaque de cada editoria de tecnologia, quantas delas são assinadas por jornalistas mulheres?

b) questões de gênero: existem nessas páginas?

c) fontes: na amostra selecionada, com que frequência as mulheres aparecem como fontes nas matérias jornalísticas de tecnologia? Para esta pesquisa, são consideradas fontes apenas aquelas cuja voz direta foi utilizada na matéria.

d) fotografias: Quando as matérias principais são acompanhadas de foto ou ilustração, em quantas delas a mulher aparece representada?

A amostra inclui as notícias principais, veiculadas em 19 de dezembro de 2013, presentes em uma edição online dos seguintes portais de tecnologia: o Link, do jornal 0 
Estado de São Paulo (SP), o Tec, da Folha de São Paulo (SP), o Tecnologia, da Gazeta do Povo (PR) e o Tecnologia, do Correio Braziliense (DF).

\section{Delimitações e cobertura das editorias de tecnologia no jornalismo brasileiro}

Para situar o lugar de pesquisa deste artigo, ponderou-se pontuais considerações sobre a prática de jornalismo em tecnologia no Brasil. Em primeiro lugar, é preciso dizer que pesquisas acadêmicas sobre as especificidades e os posicionamentos das editorias de tecnologia no Brasil são incipientes, o que torna um desafio descrevê-las. Em segundo lugar, a percepção inicial que se tem sobre elas é que não há unicidade de pensamento sobre quais os temas que devem ser tratados nesses espaços.

Enquanto algumas editorias de tecnologia dão ênfase aos aspectos ligados à cultura digital (como novas formas de produzir, compartilhar e consumir conteúdo na web, ou o desenvolvimento de experiências colaborativas com arte e software, para citar alguns exemplos), outras preferem privilegiar a abordagem economicista e utilitarista das inovações do setor, aproximando a cobertura de tecnologia a da que é realizada em editorias de Economia.

Sabe-se que o material jornalístico que atualmente compõe parte do que se entende pela temática "tecnologia" antes era comumente pertencente às seções de informática. Observa-se, porém, uma descontinuação do uso da palavra "informática" na titulação de editorias dos jornais - talvez pela associação direta do termo com a ciência da informação, numa perspectiva tecnicista. A substituição de "informática" por "tecnologia" pressupõe um leque mais amplo de assuntos a serem abordados nesses espaços editoriais.

Filomena Bomfim (1997) afirma que as características de tais editorias fazem parte de uma vertente do jornalismo científico. Citando Burkett (1990), ela descreve esse tipo de prática como aquela que tem a finalidade de explicar ou traduzir o conhecimento científico para pessoas “[...] que podem ou não ser cientistas, já que a relação científica tende a ser dirigida para fora, para audiências além da estreita especialidade científica onde a informação se origina”. (BOMFIM, 1997, p. 19).

No entanto, considerando as transformações da relação entre a tecnologia e a sociedade, ocorridas entre 1997 e 2014 - sobretudo no que tange a web 2.0. e a popularização de dispositivos móveis-, questiona-se a aproximação do jornalismo tecnológico ao jornalismo científico. Acredita-se que, enquanto segmentação temática, 
aquele pode se encaixar nas características do jornalismo especializado, embora nem sempre o faça.

Uma tendência percebida nessas editorias é que, com a obrigatória reconfiguração dos meios de comunicação, em decorrência da crise que afeta alguns modelos de negócio jornalísticos, elas vêm perdendo seu espaço e adquirindo cada vez menos importância nos jornais. 0 Link, do jornal $O$ Estado de São Paulo, por exemplo, passou por uma reformulação em abril de 2013 e deixou seu status de caderno para integrar a editoria de "Economia \& Negócios". 0 caderno Tec, da Folha de São Paulo, parou de circular desde o dia 27 de julho de 2014, e as notícias sobre tecnologia passaram a ser acomodadas nas últimas páginas da editoria "Mundo". 0 caderno de Tecnologia da Gazeta do Povo também deixou de existir no impresso, concentrando apenas em uma página temática, que circula aos sábados. Nas versões para web, os conteúdos continuam circulando a partir de uma editoria própria, em forma de seção temática no site do jornal. A redução do espaço delimitado para cobertura de temas específicos sobre tecnologia repercute também em uma diminuição da estrutura do processo de produção jornalística nesse setor.

\section{A construção social das notícias e a perspectiva de gênero}

A produção jornalística vista sob a teoria do newsmaking considera todo o processo de produção jornalística, da seleção, produção, construção até a veiculação do conteúdo informativo, considerando ainda os elementos que interagem neste percurso, tais como critérios de noticiabilidade, escolha de fonte, preocupação com tempo e espaço, organização jornalística, linha editorial e interações no campo profissional.

Neveu (2003) entende como rotina produtiva os procedimentos presentes no processo de produção jornalística, bem como na construção de uma edição de um veículo com periodicidade fixa. $\mathrm{O}$ autor ressalta que os passos para "construir o acontecimento" e a edição seguem uma "lógica de produção" sistemática. Hackett (19991, p. 138 apud TRAQUINA, 2001, p. 30) considera a presença de alguns fatores na construção da notícia:

Os critérios de noticiabilidade, as características tecnológicas de cada meio noticioso, a logística da produção jornalística, retraimentos orçamentais, inibições legais, a disponibilidade da informação das fontes, a necessidade de contar estórias, de forma inteligível e interessante, a um determinado público, a necessidade de empacotar a notícia de um modo que seja

\footnotetext{
${ }^{1}$ HACKETT, Robert. Declínio de Um Paradigma? A parcialidade e a objetividade nos estudos dos Media Noticiosos. In: TRAQUINA, Nelson (Org.). Jornalismo: questões, teorias e estórias. Lisboa: Veja, 1999, p. 101-130.
} 
compatível com o imperativo comercial de vender as audiências aos anunciantes e a aparência dos acontecimentos sociais e políticos.

Pereira Junior (2006, p. 71) aponta que

A notícia é construída no cuidado com a verificação, sobre o alicerce do levantamento de informações. Mas, como toda matéria é calcada em mediações e discursos (entrevistas, relatos, interpretações de documentos, provas e contraprovas) uma voz anularia a outra, caso não houvesse evidência "consistente".

Para Tuchman (1978), os jornalistas dão forma a um jornal, por meio de um processo de construção social da realidade. A autora analisa jornais impressos e televisionados, a estrutura interna e o aspecto burocrático da empresa, desde a hierarquia dos cargos, passando pela influência política e do Estado sobre a liberdade de expressão, o confronto entre os funcionários de um mesmo veículo, até as várias etapas pelas quais a notícia passa durante sua criação e as relações que ela envolve neste percurso.

A consulta a fontes e o uso de entrevistas fazem parte dos procedimentos adotados pelo jornalista durante o processo de construção da notícia. 0 interessante é que pesquisas de gênero mostram uma predominância na utilização de fontes masculinas no conteúdo informativo veiculado nos impressos.

Dois estudos de monitoramento de jornais e revistas, realizados pelo grupo de pesquisa Jornalismo e Gênero da Universidade Estadual de Ponta Grossa, durante os anos de 2011 e 2012, analisaram, entre outros aspectos, a presença de homens e de mulheres como fontes em seis revistas femininas (Capricho, Gloss, Nova, Cláudia, Lola e Women's Health) e uma masculina (Men's Health), dois jornais de Ponta Grossa (Diário dos Campos e Jornal da Manhã) e um de Curitiba (Gazeta do Povo).

O estudo esteve focado nas notícias que ganharam destaque nas capas das revistas supracitadas, com edições veiculadas no mês de março de 2011. Já os três jornais referidos anteriormente obdeceram ao mesmo critério de análise dos semanários, compreendendo, porém, os meses de março, abril e maio. Optou-se pela metodologia usada pelo Projeto de Monitoramento da Mídia Global (WACC), que investiga as representações das mulheres e dos homens nas notícias.

Os resultados apontaram um maior protagonismo masculino e a tendência à invisibilidade feminina, tanto nos jornais quanto nas revistas (WOITOWICZ; ROCHA, 2013). O estudo de Torres (2000) destaca semelhanças na América Latina. "As notas que dizem respeito às mulheres tiveram muito pouca cobertura em todos os meios analisados; a 
imprensa escrita foi o meio mais alheio a elas. Para cada título vinculado às mulheres, há 29 que não o fazem de modo algum". (TORRES, 2000, p. 158, tradução nossa). As mulheres também não são representadas como fontes primárias de acordo com Torres (2000, p. 158, tradução nossa):

As mulheres são muito pouco consultadas pelos meios. Pese o fato que as entrevistas são um recurso muito habitual nos informativos, tanto radiofônicos quanto televisivos, os meios não as consideram como informantes "diretas" para suas notícias.

Outro aspecto importante e inerente ao processo de produção e construção das notícias é a presença dos valores-notícia. Wolf (1995) define para cada uma das fases do processo de produção jornalística diferentes categorias de valores-notícia. Na seleção, por exemplo, entre os critérios substantivos estão: notoriedade, proximidade, relevância, novidade, tempo, notabilidade, inesperado, conflito (controvérsia) e infração (escândalo). Ainda nesta fase, em relação aos critérios contextuais aparecem: disponibilidade, equilíbrio, visualidade, concorrência e dia noticioso. Na etapa de construção estão presentes os valores-notícia de simplificação, amplificação, relevância, personalização, dramatização e consonância.

Traquina (2005) acrescenta também os valores-notícia referentes à concepção da empresa jornalística, ou seja, da linha editorial do veículo e da própria organização empresarial na linha produtiva.

O conteúdo de cada critério está relacionado com o aspecto cultural. O que é considerado novidade em um país pode não ser em outro, ou mesmo pode se alterar de uma região para outra, assim como o inesperado, relevância, entre outros. Com isso, as representações contidas nos valores-notícia reproduzem as representações da sociedade em que a notícia está inserida, no caso desta reflexão, relacionou-se com as representações de gênero. Como traz Hall et al. (19932, p. 226 apud TRAQUINA, 2001, p. 56-57) "Os media definem para a maioria da população quais os acontecimentos significativos que ocorrem, mas, também, oferecem poderosas interpretações de como compreender esses acontecimentos".

O sociólogo francês Pierre Bourdieu é um dos autores que discute a teoria da representação social. Para Bourdieu (1999), a dominação masculina atua tanto sobre o homem como sobre a mulher e está inserida no habitus e na estrutura social, fazendo parte do contexto cultural e social. Há mecanismos históricos que são responsáveis pela des-

${ }^{2}$ HALL, S. et al. Policing the crisis: mugging, the state, and law and order. London: Holmes \& Meier, 1993. 
historicização e pela eternização das estruturas da divisão sexual e dos princípios de divisão correspondentes. Assim, aquilo que na história aparece como eterno, nada mais é do que produto de um trabalho de eternização que compete a instituições como família, igreja, escola, esporte e jornalismo, que reinserem na história a relação entre os sexos tão questionada pelas visões naturalista e essencialista. Quando alguém se representa ou é representado como masculino ou feminino, subentendem-se todos esses atributos sociais. 0 mesmo discurso dominante ainda é visível nos textos jornalísticos, principalmente na mídia tradicional.

Scott (1990) indica que o discurso da mídia deve ser visto também pela perspectiva dos estudos de gênero. Nesse contexto, gênero é compreendido como uma categoria de análise, semelhante à raça e à classe social, permitindo ressignificar as relações de poder.

0 estudo do gênero, por exemplo, não se restringe a um sistema de relações determinadas apenas pelo sexo e/ou pela sexualidade, mas tem que contemplar a universalidade e a especificidade histórica de contextos em transformação. Scott (1990) concebe gênero como um elemento constitutivo das relações sociais, que está sujeito a mudanças nas representações de poder:

0 gênero implica em quatro elementos: primeiro, os símbolos culturalmente disponíveis que evocam representações simbólicas... Em segundo lugar, os conceitos normativos que põem em evidência as interpretações do sentido dos símbolos, que se esforçam para limitar e conter suas possibilidades metafóricas. Estes conceitos estão expressos nas doutrinas religiosas, educativas, científicas, políticas ou jurídicas e tomam forma típica de uma oposição binária, que afirma de maneira categórica e sem equívocos o sentido do masculino e do feminino [...]. 0 desafio da nova pesquisa histórica é fazer explodir essa noção de fixidez, é descobrir a natureza do debate ou da repressão que produzem a aparência de uma permanência eterna na representação binária do gênero. Este tipo de análise deve incluir uma noção de política bem como uma referência às instituições e à organização social - este é o terceiro aspecto das relações de gênero [...] 0 quarto aspecto do gênero é a identidade subjetiva. (SCOTT, 1990, p. 14-15).

Scott (1990) chama a atenção dos estudiosos para considerar as relações sociais e institucionais no estudo do gênero bem como o poder. 0 poder está explícito em diversas instâncias e implícito em outras, ele circula em uma sociedade, mesmo de forma desigual. Assim, o gênero é o primeiro campo, mas não é o único, no qual o poder é articulado. Ele é um meio para compreender as relações complexas entre diversas formas de interação humana em diferentes sociedades. 0 gênero é uma dimensão decisiva da organização da igualdade e da desigualdade. 
Saffioti (1979) mostra que para se entender a construção do gênero, deve-se considerar o processo de modelagem conquistada dos seres humanos, envolvendo as classes sociais e a trama de relações sociais entre mulheres, entre homens e entre homens e mulheres.

Já Lauretis (1994) estabelece uma relação entre o conceito de gênero e a concepção de ideologia discutida por Althusser (1970), sendo o primeiro uma instância da ideologia. Nesse sentido, considera todas as instituições da sociedade (política, educação, leis, justiça, família, igreja) atuando nas representações do gênero.

Sob este aspecto, as mulheres também devem ser vistas como seres históricos, como sujeitos de relações reais, motivadas pela contradição cultural de mulheres que se situam dentro e fora do gênero, simultaneamente dentro e fora da representação. 0 sujeito é formado pela representação do gênero (dentro do seu referencial androcêntrico) e o que essa representação torna irrepresentável. São dois espaços diferentes que formam o movimento: o espaço discursivo, representado pelos discursos hegemônicos, e o space-off, que são os espaços sociais e discursivos que existem nas margens dos discursos hegemônicos, no "contra práticas" e nas novas formas de comunidade. Esses dois espaços coexistem, mas também estão em contradição.

0 poder se distribui por todas as instituições interligadas e móveis que atuam separadas, mantendo a estrutura da sociedade. Ele atua em pequenos focos e não se limita a apenas dois extremos, os que exercem o poder e os que são dominados. Há uma correlação de forças atuando com características assimétricas. 0 gênero, assim, não é determinado apenas por um conceito universal, ele passa a ser visto como uma categoria de análise. Ele está presente nas relações de poder, nas instituições e, também, muda de acordo com a sociedade, cultura e período histórico. A mulher passa a ser vista como um sujeito múltiplo.

0 desafio do estudo proposto é olhar para o jornalismo de tecnologia, considerando as especificidades do jornalismo sob a perspectiva de gênero, travando um diálogo entre estes dois campos na tentativa de entender como se dá a participação feminina nos cadernos de tecnologia tanto como produtoras de conteúdo quanto na construção do conteúdo (texto e foto) sob a perspectiva de gênero.

\section{Análise das editorias de tecnologia: onde está a mulher?}

O Estado de São Paulo, Folha de São Paulo, Correio Braziliense e Gazeta do Povo foram os escolhidos porque, entre a lista dos sites mais acessados do Brasil em 2013, segundo o 
portal Actionable Analytics for the Web (Alexa), esses eram respectivamente os jornais (que possuíam editorias online de tecnologia) mais bem colocados do ranking (ALEXA, 2013). As notícias analisadas foram aquelas consideradas de destaque pelo próprio veículo, ou seja, que aparecem em posição privilegiada diante das demais no planejamento gráfico das páginas.

O Link, do Jornal O Estado de São Paulo, possui três matérias de destaque em sua página, que ficam se alternando em um quadro, localizado na parte superior esquerda do site. As três notícias de destaque no dia 19 de dezembro eram: "Zuckerberg vende ações do Facebook" (1), "LG anuncia primeiro desktop com Chrome OS" (2), e "Bill Gates participa do amigo-secreto do Reddit" (3). Destas, a primeira vinha com a assinatura da agência de notícias Reuters e as outras duas com a assinatura de repórter do sexo masculino. Nenhuma das destacadas nesse dia foi assinada por uma mulher. E nenhuma envolvia temática relacionada a gênero, como se pode perceber pelos títulos: duas tratam de negócios e a terceira tem como critério de noticiabilidade a notoriedade de Bill Gates.

De fato, os valores-notícia, que os jornalistas frequentemente sugerem ser algo de intrínseco aos acontecimentos, para serem deduzidos utilizando o 'sentido noticioso', são códigos culturalmente específicos de contar 'estórias'. (BIRD; DARDENNE, 1993, p. 268).

Foi possível avaliar que a apuração das notícias foi mínima. É curioso constar que todas tinham quatro parágrafos pequenos, nenhum subtítulo e que trouxeram apenas uma fonte primária. Com relação às fontes femininas, apenas uma mulher aparece na notícia sobre o amigo secreto de Bill Gates. Ela não teve o nome identificado (usa o codinome "NY1227") e sua voz direta aparece em uma frase que ocupa uma linha, apenas. A única aparição da fonte feminina não é para se referir a temas correlatos à tecnologia, nem como uma consulta a uma profissional da área, muito menos como consumidora. A referência é a sua relação pessoal com Bill Gates. A fonte feminina é representada como "amiga de Bill Gates".

Quanto às fotografias, todas as matérias de destaque no Link levaram imagens ilustrativas. Nenhuma, no entanto, continha uma mulher. Na única notícia que utiliza uma fonte feminina, a foto que aparece é a de Bill Gates, com os presentes que escolheu para dar a ela no amigo secreto. A imagem da foto reitera que o assunto é ele por sua notoriedade $\mathrm{e}$ não a fonte feminina.

No caderno de tecnologia da Folha de São Paulo, Tec, foi publicado o dobro de notícias: seis em destaque. Cinco delas aparecem de forma alternada, em um quadro à 
esquerda na página, e uma aparece como manchete (com o título em fonte maior do que o das demais), na coluna do meio. Foi possível perceber que elas não são datadas no mesmo dia, o que sugere uma atualização regular, mas não com volume considerável para mudar todos os destaques.

Os destaques que aparecem no dia da análise são: “Aproximação entre versões grande e pequena do iPad dificulta escolha" (1), "Google lança app para localizar aparelhos com Android perdidos ou roubados" (2), "Brasileiros lançam app de avaliação de mulheres em resposta ao Lulu" (3), "Carro feito com 500 mil peças de Lego é movido a ar e chega a mais de 30 km/h" (4), “Amazon completa um ano no Brasil e lança novo leitor Kindle" (5), e "Para aumentar controle do Facebook, Mark Zuckerberg venderá US\$ 2,3 bilhões em ações" (6).

Dentre os destaques, quatro foram assinadas por homens. A quinta era "das agências de notícias de São Paulo", e a outra não estava assinada. Nenhuma jornalista assinou as matérias do Tec desta amostra. Das seis notícias, uma envolvia temática de gênero, as restantes tratavam de negócios.

A "notícia" que envolve gênero fala sobre o aplicativo (app) "Clube do Bolinha”, criado por brasileiros de Indaiatuba (SP), em resposta ao "Lulu", aplicativo que permite às mulheres dar notas aos homens que são contatos no Facebook. 0 aplicativo, disponível para Android, permite aos homens dar notas às mulheres com quem saíram, e, entre os adjetivos possíveis (atribuídos aos perfis via hashtag), estão \#MariaGasolina, \#SóFazMiojo", “\#VidaLoka”, “\#TopaTudo” e “\#Bigodinho”. A proposta denigre a imagem feminina, faz uma representação de gênero pautada em estereótipos machistas e a única fonte ouvida foi um homem -um dos criadores do aplicativo. Destaque para uma de suas falas, utilizadas em voz direta: “Se você está no 'mercado', está sujeito a isso: as pessoas podem te aprovar e podem não te aprovar". 0 título "Brasileiros lançam app de avaliação de mulheres em resposta ao Lulu" é provocativo, como se fosse uma retaliação a um aplicativo lançado para mulheres.

Ainda com relação ao texto publicado no Tec, duas fotos ilustravam a notícia e em ambas aparecem mulheres. Na primeira delas - que é um print da interface do aplicativo -, aparecem duas duas mulheres de biquíni, com suas respectivas notas e hashtags atribuídas. Na mesma imagem (à esquerda) aparece o logotipo do aplicativo, que é um bumbum feminino, branco, usando fio dental vermelho. A segunda é uma imagem divulgada pelos desenvolvedores do "Clube do Bolinha", em sua página do Facebook, na qual aparece um carro estragado, parado na lateral direita de uma pista, motor aberto, com uma mulher vestida de noiva deitada embaixo, resolvendo o problema. Do lado esquerdo, próximo ao 
capô, o "noivo" encostado, de óculos escuros e olhando para cima com expressão orgulhosa. A legenda: "Essa é para casar". As representações de gênero nas fotografias reproduzem, no primeiro caso, a mulher como objeto sexual e, no segundo, resolvendo o problema do carro, sempre em uma relação desigual de gênero, seja em uso ou em confronto.

Das seis matérias de destaque, apenas três tinham voz direta com fonte primária e nenhuma delas era mulher. Quanto às fotos, somente apareceu mulheres nas do texto sobre o "Clube do Bolinha". É interessante observar que, algumas vezes, nas análises constam a presença de fotografias, mas não incluem nem homens nem mulheres. Nesses casos (tanto no Tec quanto em outras editorias de tecnologia), na maioria das vezes, as fotos são de aparelhos.

É preciso dizer que a definição das principais notícias da editoria de Tecnologia do Correio Braziliense foi mais difícil comparado aos demais. 0 site tem seis notícias principais na parte superior da página. Dessas, quatro possuíam imagens na capa e as outras duas não. Optou-se por considerar apenas as quatro acompanhadas de fotos. São elas: "Amazon anuncia chegada do novo Kindle Paperwhite ao Brasil" (1), "Bush pai abre conta no Twitter aos 89 anos e homenageia Mandela" (2), "Samsung perde batalha judicial contra Apple na guerra das patentes" (3), "Envy X2, da HP, é bonito, mas tem preço alto e falha em pequenos detalhes" (4).

Dessas quatro, uma delas não possuía autoria. Outras duas estavam identificadas como sendo da agência de notícias France Presse e a única matéria assinada por repórter levava o nome de um homem (notícia 4). As fontes de voz direta praticamente não aparecem nos textos da página sobre tecnologia. Apenas duas notícias levavam declarações entre aspas e, em ambos os casos, eram falas masculinas.

As fotografias encontradas reforçam uma observação já colocada anteriormente: algumas fotos e ilustrações não possuem nem homem nem mulher. Todas eram fotografias de aparelhos eletrônicos. No caso da notícia sobre o Twitter de Bush, foi escolhida uma imagem, em print screen, da conta pessoal do ex-presidente americano, na rede social.

A editoria de Tecnologia do jornal Gazeta do Povo, por sua vez, veiculou cinco destaques na página, todos passando de forma alternada, com ilustrações, em uma coluna única na parte superior. Do total, uma notícia advém da Agência 0 Globo e as outras quatro são assinadas por um repórter do jornal e do sexo masculino. Os destaques foram: "Sete dúvidas comuns de quem tem smartphone" (1), "Dúvida cruel: qual console comprar?" (2), "Robôs ganham espaço nas redes sociais" (3), "Moto G é barato sem deixar de ser esperto" e 
"Trinta opções de aparelhos 4G no mercado brasileiro". Como se pode ver, nenhuma delas inclui temática ligada a gênero.

Em concordância com a tendência mostrada pelas páginas dos outros três jornais, não há presença de fontes femininas na amostra. A Gazeta do Povo costuma trazer um número maior de pessoas ouvidas em cada matéria, com relação aos outros jornais. Uma observação interessante é que todas as fontes masculinas ouvidas eram especialistas em tecnologia, ou ocupavam cargo de gerência ou chefia nas empresas envolvidas nas notícias.

Figuras femininas apareceram duas vezes entre o total de fotografias analisadas nesse veículo. Uma delas é mostrada apenas de perfil, sem identificação, mexendo em um smartphone (notícia 1). Ela não foi fonte da matéria em questão. A outra aparição feminina é o print screen de um perfil "bot" (um robô programado para fazer postagens através de combinações de palavras) no Twitter, de uma suposta jornalista de nome Carina Santos. Nas duas imagens a identidade feminina não é colocada. Tanto no primeiro caso quanto no segundo, é a mulher e o símbolo feminino que sãorepresentados como uma ilustração.

\section{Considerações finais}

A análise da amostra selecionada, que incluiu as páginas de tecnologia de quatro jornais brasileiros durante um dia, revela, em um primeiro momento, a ausência de notícias assinadas por jornalistas mulheres, o que sugere que as editorias de tecnologia ainda não absorveram a tendência do mercado jornalístico atual. Como foi mencionado, há uma feminização do jornalismo, segundo dados do estudo "Perfil do Jornalista Brasileiro", da Universidade Federal de Santa Catarina (UFSC), pois existe, no Brasil, mais mulheres atuando no mercado jornalístico do que homens.

A segunda consideração é a respeito dos temas ligados a gênero: na amostra de 18 textos, somente um - publicado no caderno Tec, da Folha de São Paulo - tratou sobre questões de gênero. 0 tipo de abordagem, no entanto, revela uma legitimação da postura do estereótipo machista, ao noticiar um aplicativo que denigre a imagem feminina.

A ausência de fontes femininas, bem como a ausência de problematização sobre o comportamento dos brasileiros criadores do aplicativo e o tipo de fotos apresentadas na notícia só reforçam este posicionamento. É interessante lembrar que, poucas semanas antes, ganhou destaque nos jornais o anúncio do falso lançamento de um aplicativo chamado Tubby, que teria como função ser um espaço "para os homens avaliarem as mulheres". 0 
escândalo do Tubby mobilizou até o Poder Judiciário, que chegou a proibir o app no Brasil, com base na Lei Maria da Penha.

0 aplicativo, no entanto, nunca existiu. Na verdade, era uma brincadeira - depois revelada por seus criadores em um vídeo no Youtube - cuja proposta era "conscientizar as pessoas dos limites da exposição da intimidade e dos riscos da violação da intimidade". Decepcionados com a inverdade do Tubby e ignorando a mensagem passada pelos seus criadores, outros brasileiros decidiram desenvolver um aplicativo avaliador de mulheres, desta vez para valer: o "Clube do Bolinha", retratado na matéria do Tec, da Folha de São Paulo.

Há uma predominância de fontes masculinas, as mulheres não são representadas nessas editorias como profissionais da área, empresárias, executivas ou usuárias de tecnologia. Os especialistas consultados ou fontes que ocupam altos cargos nas empresas de tecnologia são majoritariamente homens. Isso revela que no processo de construção da notícia, na amostra analisada, tanto o jornalista dos jornais estudados quanto os profissionais das agências de notícias priorizaram as fontes masculinas. Fica a dúvida se de fato não há uma mulher especialista/executiva que pudesse ser entrevistada, ou se foi uma escolha do repórter pela fonte masculina. Porém sabe-se que a mulher ocupa um espaço reconhecido como usuária de tecnologia.

Embora haja ausência de fontes femininas nos textos, algumas das fotos encontradas retratam mulheres, sejam representadas em um papel secundário e ilustrativo (uma não identificada; uma foto de avatar feminino que, na verdade, era um robô) ou com estereótipo machista e de desigualdade em relação ao gênero masculino (nas fotos publicadas na notícia sobre o "Clube do Bolinha", em posições insinuantes). As representações de gênero no conteúdo informativo, seja texto ou imagem, não mostram as mulheres nas posições que ocupam e desenvolvem no cotidiano, tais como profissionais, filhas, mães, companheiras, consumidoras, produtoras, enfim as diferentes situações e relações que desempenham no dia a dia e nas suas relações sociais, econômicas, políticas, familiares e pessoais.

Nas editorias analisadas as representações femininas, quando aparecem, reiteram a cultura machista, desconsiderando o contexto que se configura na sociedade século XXI, em que a mulher corresponde, no Brasil, a 46,1\% da população economicamente ativa, segundo dados do IBGE, referente ao ano de 2011, e a um potencial consumidor de tecnologia (IBGE, 2011). 
O estudo chama a atenção para a forma como o jornalismo que escreve sobre tecnologia traz as representações de gênero no conteúdo informativo, bem como o descompromisso em ouvir fontes femininas. Outro dado é a baixa participação de jornalistas mulheres nessas coberturas. A pesquisa não aponta os motivos desta reduzida participação, se parte de um desinteresse por parte das próprias profissionais ou se diz respeito à demanda das chefias das editorias de tecnologia.

Tal informação seria interessante para uma investigação futura. Inclusive para verificar se as representações estereotipadas, assim como a busca de fontes masculinas, devem-se ou não ao fato da autoria dessas produções jornalísticas ser predominantemente masculina. Isso acende um alerta: apesar de o tempo ter reconfigurado as representações de gênero na sociedade contemporânea e a participação feminina aumentar no campo do jornalismo, as editorias de tecnologia parecem ainda não acompanhar essa tendência. Esse desequilíbrio reforça a importância de continuar e ampliar os estudos no campo jornalístico sobre as relações entre o processo de construção das notícias e as representações de gênero.

\section{Referências}

ACTIONABLE ANALYTICS FOR THE WEB (ALEXA). Top sites in Brazil. 2013. Disponível em: <http://www.alexa.com/topsites/countries/BR>. Acesso em: 06 jun. 2014.

ALTHUSSER, L. Ideologia e Aparelhos ideológicos de estado. Lisboa: Presença 1970.

BIRD, S.E; DARDENNE, R.W. Mito, registros e 'estórias': explorando as qualidades narrativas das notícias. In: TRAQUINA, N. (Org.). Jornalismo: questões, teorias e 'estórias'. Lisboa: Veja, 1993. p. 263-277.

BOMFIM, F. M. A. A informação nos cadernos de informática nos grandes jornais. UFMG, 1997.

BOURDIEU, P. A dominação masculina. Rio de Janeiro, Betrand Brasil, 1999.

GUERRA, Y. H. Mujer y periodismo en Cuba: un itinerario singular. In: COLÓQUIO MULHER E SOCIEDADE: AS REPRESENTAÇÕES DE GÊNERO NA CONTEMPORANEIDADE, 3., 2014, Ponta Grossa. Anais... Ponta Grossa: UEPG, 2014.

INSTITUTO BRASILEIRO DE GEOGRAFIA E ESTATÍSTICA (IBGE). Mulher no mercado de trabalho. 2011. Disponível em:

http://www.ibge.gov.br/home/estatistica/indicadores/trabalhoerendimento/pme_nova/M ulher_Mercado_Trabalho_Perg_Resp_2012.pdf. Acesso em: 15 jun. 2014.

LAURETIS, T. A tecnologia do gênero. In: HOLLANDA, H. B. (Org.). Tendências e impasses: o feminismo como crítica da cultura. Rio de Janeiro, Rocco, 1994. p. 206-242. 
PEREIRA JUNIOR, L. C. A apuração da notícia: métodos de investigação na imprensa. Petrópolis: Vozes, 2006.

NEVEU, É. Sociologia do Jornalismo. Porto, Porto Editora, 2005.

PERFIL do Jornalista Brasileiro. Florianópolis: UFSC, 2013. Disponível em:

<http://www.perfildojornalista.ufsc.br/dados>. Acesso em: 10 jun. 2014.

ROSALES, B. Jonalismo Peru: as mulheres dominam, mas não mandam. 2009. Disponível em <http://www.ipsnoticias.net/portuguese/2009/04/america-latina/jornalismo-peru-asmulheres-dominam-mas-nao-mandam>. Acesso em: 10 jun. 2014.

SAFFIOTI, H. I. B. A mulher na sociedade de classe. Petrópolis: Vozes, 1979.

SCOTT, J. Gênero, uma categoria útil de análise histórica. Revista Educação e Realidade, Porto Alegre, v. 16, n. 2, p. 71-99, jul./dez. 1990.

TUCHMAN, G. Making news: a study in the construction of reality. New York: The Free Press, 1978.

TRAQUINA, N. Teorias do Jornalismo: a tribo jornalística - uma comunidade interpretativa transnacional. Florianópolis: Editora Insular, 2005. v. 2.

TRAQUINA, N. O Jornalismo português em análise de casos. Lisboa: Editorial Caminho, 2001.

TORRES, C. Género y comunicación: el lado oscuro de los medios. Santiago: Ediciones de la Mujeres, 2000.

WOITOWICZ, K. J.; ROCHA, P. M. Estudos de gênero no Jornalismo: perspectivas de análise das mulheres jornalistas e das representações femininas. In. WOITOWICZ, K. J.; ROCHA, P. M. (Org.). Marcas \& discursos de gênero: produções jornalísticas, representações femininas e outros olhares. Ponta Grossa: Editora UEPG, 2014. P. 131-150. 


\title{
The feminization of journalism and lack of gender perspective in sections of technology in Brazil
}

\begin{abstract}
Female participation in Brazilian journalism is larger than the male in the 21th century. However, the process of news production is still the same as before with respect to the perspective of gender studies. Still dominated by male sources in journalistic discourse, especially in editorial policy and economics. In this sense, this article aims to look at a new editorship compared with the politics and economics; it is the editorship of technology (online version). The aim is to verify the presence of women both as producers of news sources as well as gender representations disseminated in the informational content, including photos and themes of the news. The methodology includes bibliographical research in journalism and gender studies, on the theory of newsmaking and gender concept. It was observed four Brazilians newspaper, Gazeta do Povo, Correio Braziliense, Folha de São Paulo and O Estado de São Paulo, from journalistic categories established based on the theoretical framework in journalism. The results show that the number of female professionals working in the technology section is practically non-existent and that the concern with gender issues is minimal in these editorials. This perception reinforces the importance of continuing research and debate in this area.
\end{abstract}

\section{Keywords}

Journalism. Technology section. Gender representation. Newsmaking. Feminization of Journalism.

Recebido em 08/04/2014

Aceito em 22/10/2014 